\title{
Knowledge about male circumcision and perception of risk for HIV among youth in Harare, Zimbabwe
}

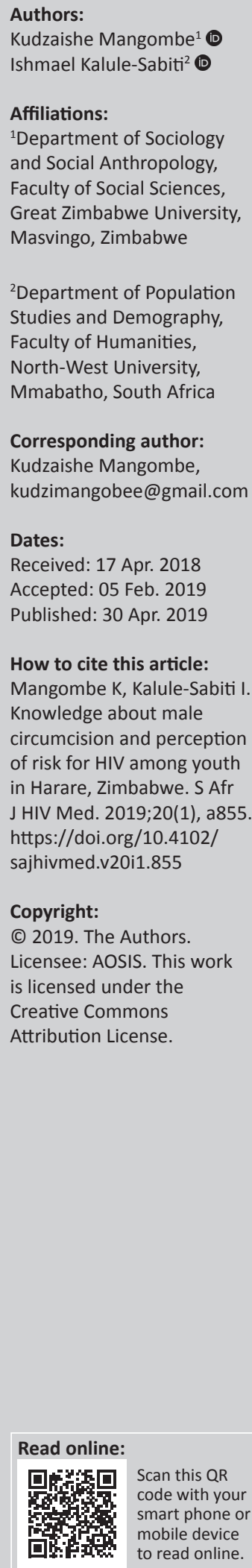

Background: Male circumcision will require high uptake among previously non-circumcising countries to realise the impact of circumcising in preventing HIV. Little is known about whether youths are knowledgeable about male circumcision and its relationship with HIV prevention and their perception of risk of HIV infection.

Objective: This article aimed to ascertain youth's knowledge about male circumcision and perception of risk of HIV infection.

Methods: A quantitative study on 784 youth (men aged 15-35 years) was conducted in Harare, Zimbabwe, after obtaining their consent. Multivariate analysis examined the associations between background characteristics and knowledge about male circumcision and the perception of risk of HIV infection.

Results: The results revealed that age was a significant predictor of knowledge about male circumcision among youth in Harare, as was educational attainment and ever having tested for HIV. In addition, youth who had heard of voluntary medical male circumcision were more likely to have high knowledge of male circumcision compared to those who had never heard of it. The results also showed that male circumcision status was associated with higher knowledge about male circumcision compared to those who were not circumcised. The study also found that educational attainment, belonging to the Shona ethnic group, never having tested for HIV and disapproval of voluntary counselling and testing prior to male circumcision were associated with the perception of risk of HIV infection.

Conclusion: The study provides two recommendations: the need to strengthen perceived susceptibility to HIV among the youth and the need for advocacy on the health benefits of male circumcision.

Keywords: Knowledge about male circumcision; Perception of risk to HIV; Youth; Zimbabwe; Voluntary medical male circumcision; Voluntary HIV counselling.

\section{Introduction}

The aim of the study was to identify the sociodemographic factors associated with knowledge about male circumcision and the perception of risk of HIV infection among youth in Harare, Zimbabwe. Male circumcision as a subject is at the helm of HIV prevention. The eastern and southern Africa regions are most affected by HIV, with the number of people on treatment more than doubling since 2010, reaching nearly 10.3 million people, resulting in HIV- and AIDS-related deaths in the region decreasing by $36 \%$ since $2010 .{ }^{1}$ According to UNAIDS, the region has also witnessed the largest reduction in new adult HIV infections. There were about 40000 fewer new adult HIV infections in the region in 2015 than in 2010, a 4\% decline. ${ }^{1}$

Although strides have been made concerning improved sexual behaviour in most countries, some countries in sub-Saharan Africa have detected low condom use and an increase in the number of sexual partners in their surveys. ${ }^{2}$ Recent reports show that sexually transmitted infections (STIs) are increasing among certain population groups, including urban youth in Harare. ${ }^{3}$ Considering the higher levels of STIs among the urban youth, there is need to focus attention on knowledge about male circumcision and the perception of risk of HIV infection research in urban areas as a way to curb further HIV and sexually transmitted infections. Both observational and ecological studies have shown that male circumcision reduces female-to-male HIV transmission, ${ }^{4,5,6}$ and three randomised controlled trials ${ }^{7,8,9}$ have shown that male circumcision has the potential to significantly alter the HIV epidemic in countries with high HIV prevalence and low circumcision rates. Thus, in sub-Saharan Africa, there is currently a push for male circumcision to reduce the risk of HIV infection in previously non-circumcising communities. 
One of the potential challenges in adopting male circumcision in non-circumcising countries has been a lack of knowledge regarding the benefits in reducing HIV transmission. ${ }^{10,11,12,13}$ Studies on knowledge about male circumcision have been conducted previously, ${ }_{1}^{10,11,14,15}$ some of which have found that the perception of risk of HIV infection is a predisposition for willingness to circumcise. $16,17,18,19,20$ However, most of these studies did not exclusively cover male youth age 15-35 years who reside in urban areas.

Little is known about the impact of sociodemographic characteristics on knowledge about male circumcision and perception of risk of HIV infection among youth in Zimbabwe despite the fact that this is a key population in the fight against HIV. This study confines itself to youth aged 15-35 years, which is in line with the African Charter definition. ${ }^{21}$

\section{Methods \\ Design, setting and sample}

A cross-sectional study with a closed-ended questionnaire was conducted in Harare among male youth. The sample was calculated using Kish's ${ }^{22}$ sample size determination. This yielded a target population of 853 men aged $15-35$ years. A total of 783 youth were interviewed, yielding a response rate of $92 \%$. The study used the 2012 Zimbabwe Census as the sampling frame, and a three-stage sampling design was employed. Firstly, the process involved the selection of primary sampling units, which were the Enumeration Areas (EAs). The second stage involved the selection of households as secondary sampling units (SSUs). The last stage involved the selection of respondents within the households in the selected EAs. An eligible participant was one male household member between the ages of 15 and 35 years. When multiple households existed within a single dwelling unit, a Kish grid was used to randomly select a responding household, and one member of the selected household was eligible to participate. If the selected household had no eligible respondent, the next household within the same dwelling unit was selected. Thus, a Kish grid was used in the selection of a respondent in a multiple-respondent household and multiple-dwelling units.

\section{Measures}

\section{Dependent variables}

Knowledge about male circumcision was measured by 10 items measured at the nominal level. The responses for each item were coded 0 and 1 , with 0 indicating that an individual did not have knowledge about that particular question and 1 indicating that an individual did have knowledge about it. A knowledge score was obtained by summing up the individual knowledge questions. The score ranged from 0 to 10. The knowledge score was dichotomised. Previous studies have also dichotomised knowledge scores in a similar way. ${ }^{23}$ Studies have confirmed that dichotomisation of continuous variables makes interpretation easy and helps in simplifying analyses or presentation of results. ${ }^{24,25}$ The dichotomisation was done at mean score (7.79). A value of $0-7.78$ indicated that the respondents had low knowledge about male circumcision, and a score from 7.79 to 10 indicated that the respondents had high knowledge about male circumcision. For modelling purposes, a dummy variable was created, with 0 indicating respondents had low knowledge about male circumcision and 1 for those respondents who had high knowledge about male circumcision.

Perception of risk of HIV infection was created from responses to a direct question: 'Do you think you are at risk of HIV infection'? The responses were as follows: 'Yes, at higher risk' (assigned a value of 3); 'Yes, at low risk' (assigned 2); 'No, not at risk at all' (assigned 1).

\section{Sociodemographic variables}

The respondents were asked about their age in completed years, and these were categorised into 5-year age groups: 15 19, 20-24, 25-29 and 30-35 years. Education was categorised as primary, secondary and higher than secondary. Marital status was categorised as never married, married or living together, and never formerly married. Wealth status was measured using a household goods index, which was recoded into low, medium and high wealth status. The measure was derived from the presence of 10 household assets within the respondent's household: generator, solar panel, radio, television, refrigerator, non-mobile telephone, computer, washing machine, car and electricity connected to the dwelling unit. Employment status was classified into unemployed or employed. Religion was categorised into mainline Christian, Pentecostal, apostolic sect, other Christian and no religion, while ethnicity was categorised into Shona or other. Respondents were also asked whether they had ever tested for HIV. The responses were 'yes' or 'no'. Respondents were asked whether they approved of voluntary counselling and testing (VCT) prior to circumcision (yes or no). Lastly, respondents were asked whether they had ever heard of voluntary medical male circumcision (VMMC) (yes or no).

\section{Data analysis}

Data management and statistical analyses were performed using SPSS version 22. The chi-square independence test was used to compare the various sociodemographic and dependent variables. A binary logistic regression model was used to identify predictors of knowledge about male circumcision. Multinomial logistic regression was used to predict the net effect of the predictor variables (background characteristics) on perception of risk to HIV infection. In the model, the reference category for the dependent variable was 'No, not at risk at all'.

\section{Ethical consideration}

Ethical clearance was granted by the relevant ethics council (Ethics number: North-West University [NWU 00210-14-A9] and Medical Research Council of Zimbabwe [MRCZ/A/1848]). A written informed consent was obtained from all the study participants after describing the objectives of the study to them. In addition, the respondents were assured of confidentially and anonymity. 


\section{Results}

\section{Demographic characteristics of respondents}

Table 1 presents the frequency distribution of background characteristics of the respondents. Almost equal proportions were distributed in the four age groups. The highest proportion of the respondents had never been married (63\%), had achieved secondary education $(78.8 \%)$, were employed (56\%) and had ever been tested for HIV (65.3\%); $90.6 \%$ of the respondents were of the Shona ethnic group, and most of them were not circumcised $(84.9 \%)$. In addition, $33.8 \%$ of the respondents were mainline Christians, $78.2 \%$ did not approve of HIV testing prior to circumcision, and almost all (96.8\%) had ever heard VMMC.

Table 2 presents the frequency distribution of the respondents' knowledge about male circumcision. It is evident from the

\begin{tabular}{|c|c|c|}
\hline Variable & Frequency & Percentage \\
\hline \multicolumn{3}{|l|}{ Age group } \\
\hline $15-19$ & 182 & 23.2 \\
\hline $20-24$ & 229 & 29.2 \\
\hline $25-29$ & 192 & 24.5 \\
\hline $30-35$ & 181 & 23.1 \\
\hline \multicolumn{3}{|l|}{ Marital status } \\
\hline Married or living together & 263 & 33.5 \\
\hline Formerly married & 26 & 3.4 \\
\hline Never married & 495 & 63.1 \\
\hline \multicolumn{3}{|l|}{ Education } \\
\hline Primary & 37 & 4.7 \\
\hline Secondary & 617 & 78.8 \\
\hline Higher & 129 & 16.5 \\
\hline \multicolumn{3}{|l|}{ Wealth status } \\
\hline Low & 276 & 35.2 \\
\hline Medium & 248 & 31.6 \\
\hline High & 260 & 33.2 \\
\hline \multicolumn{3}{|l|}{ Employment status } \\
\hline Employed & 439 & 56.0 \\
\hline Unemployed & 345 & 44.0 \\
\hline \multicolumn{3}{|l|}{ Religion } \\
\hline Mainline & 265 & 33.8 \\
\hline Pentecostal & 193 & 24.6 \\
\hline Apostolic sect & 169 & 21.6 \\
\hline Other Christian & 83 & 10.6 \\
\hline No religion & 74 & 9.4 \\
\hline \multicolumn{3}{|l|}{ Ethnic group } \\
\hline Shona & 710 & 90.6 \\
\hline Ndebele & 23 & 9.4 \\
\hline \multicolumn{3}{|l|}{ Ever tested for HIV } \\
\hline Yes & 512 & 65.3 \\
\hline No & 272 & 34.7 \\
\hline \multicolumn{3}{|l|}{ Approval of VCT prior to MC } \\
\hline Yes & 171 & 21.8 \\
\hline No & 613 & 78.2 \\
\hline \multicolumn{3}{|l|}{ Ever heard of VMMC } \\
\hline Yes & 759 & 96.8 \\
\hline No & 25 & 3.2 \\
\hline \multicolumn{3}{|l|}{ Circumcision status } \\
\hline Yes & 118 & 15.1 \\
\hline No & 666 & 84.9 \\
\hline Total & 784 & 100.00 \\
\hline
\end{tabular}
male circumcision. table that more than 9 in 10 respondents (94.1\%) knew that it is recommended that a circumcised man still use a condom. Moreover, $7.4 \%$ of the respondents knew that male circumcision should be integrated with other HIV prevention methods. About 8 in 10 (81.4\%) of the respondents indicated that an HIV-negative woman can contract HIV after having unprotected sex with an HIV-positive uncircumcised man. Reversing the question, about the same percentage $(83.7 \%)$ indicated that an HIV-negative circumcised man could contract HIV after having unprotected sex with an HIV-positive woman.

A little more than 8 in 10 (82.2\%) of the respondents indicated that male circumcision was not as good as an invisible condom. On the other hand, $82.7 \%$ indicated that male circumcision reduces the chances of HIV transmission. With regards to male circumcision reducing penile cancer, $53.2 \%$ indicated that male circumcision reduces penile cancer. More than 9 in 10 (92.7\%) indicated that male circumcision improves penile hygiene, and about the same proportion (92.6\%) indicated that male circumcision alone can prevent HIV infection. Fewer than half $(46.8 \%)$ of the respondents were aware that it was recommended that circumcised men abstain from sexual intercourse for a minimum period of 6 weeks following circumcision. More than two-thirds (66.5\%) of the respondents were able to define male circumcision.

Table 3 shows the bivariate relationship between the background characteristics and knowledge about male circumcision. The results showed that there was a significant association between age and knowledge about male circumcision. Knowledge about male circumcision increased with age. A higher percentage of respondents who were aged 30-35 years had high knowledge about male circumcision (88.4\%) compared to those who were aged 25-29, 20-24 and 15-19 (80.2\%, 79.9\% and 71.4\%, respectively; $p<0.001)$. A higher proportion of respondents who had attained a higher level of education had high knowledge about male circumcision (93.8\%) compared to those who had attained primary and secondary education $(77.7 \%$ and $70.3 \%$, respectively; $p<0.000)$.

High knowledge about male circumcision was more common in respondents in the high wealth status group (83.8\%)

TABLE 2: Proportion of respondents who answered correctly to the knowledge questions about circumcision $(n=784)$.

\begin{tabular}{|c|c|c|}
\hline Variable & Yes & Percentage \\
\hline $\begin{array}{l}\text { Is male circumcision a surgical removal of the end of the } \\
\text { foreskin of the penis? }\end{array}$ & 521 & 66.5 \\
\hline $\begin{array}{l}\text { Is circumcision as good as an 'invisible condom' in preventing } \\
\text { HIV transmission? }\end{array}$ & 648 & 82.2 \\
\hline Does male circumcision reduce the chances of transmitting HIV? & 668 & 85.2 \\
\hline Does male circumcision reduce penile cancer? & 417 & 53.2 \\
\hline Are circumcised men still recommended to use condoms? & 738 & 94.1 \\
\hline Does male circumcision improve penile hygiene? & 727 & 7.4 \\
\hline Can male circumcision alone prevent HIV contraction? & 726 & 92.6 \\
\hline $\begin{array}{l}\text { Can an HIV-negative woman contract HIV or STI after having } \\
\text { unprotected sex with an HIV-positive circumcised man? }\end{array}$ & 638 & 81.4 \\
\hline $\begin{array}{l}\text { Can an HIV-negative circumcised man contract HIV or STI } \\
\text { after having unprotected sex with an HIV-positive woman? }\end{array}$ & 656 & 83.7 \\
\hline $\begin{array}{l}\text { After being circumcised must a man abstain from sexual } \\
\text { intercourse for six weeks? }\end{array}$ & 367 & 46.8 \\
\hline
\end{tabular}


TABLE 3: Background characteristics by knowledge about male circumcision.

\begin{tabular}{|c|c|c|c|c|c|}
\hline Variable & $\begin{array}{c}\text { Low } \\
\text { knowledge (\%) }\end{array}$ & $\begin{array}{c}\text { High } \\
\text { knowledge (\%) }\end{array}$ & $\chi$-value & $p$ & Total \\
\hline Age & & & 16.325 & 0.001 & \\
\hline $15-19$ & 28.6 & 71.4 & - & - & 182 \\
\hline $20-24$ & 20.1 & 79.9 & - & - & 229 \\
\hline $25-29$ & 19.8 & 80.2 & - & - & 192 \\
\hline $30-35$ & 11.6 & 88.4 & - & - & 181 \\
\hline Marital status & & & 10.197 & 0.006 & \\
\hline Married or living together & 13.7 & 86.3 & - & - & 263 \\
\hline Formerly married & 19.2 & 80.8 & - & - & 26 \\
\hline Never married & 23.4 & 76.6 & - & - & 495 \\
\hline Education & & & 19.618 & 0.000 & \\
\hline Primary & 29.7 & 70.3 & - & - & 37 \\
\hline Secondary & 22.3 & 77.7 & - & - & 618 \\
\hline Higher & 6.2 & 93.8 & - & - & 129 \\
\hline Wealth status & & & 5.616 & 0.060 & \\
\hline Low & 24.3 & 75.7 & - & - & 276 \\
\hline Medium & 19.4 & 80.6 & - & - & 248 \\
\hline High & 16.2 & 83.8 & - & - & 260 \\
\hline Employment status & & & 8.184 & 0.004 & \\
\hline Employed & 16.4 & 83.6 & - & - & 439 \\
\hline Unemployed & 24.6 & 75.4 & - & - & 345 \\
\hline Religion & & & 4.425 & 0.352 & \\
\hline Mainline & 17.0 & 83.0 & - & - & 265 \\
\hline Apostolic sect & 21.9 & 78.1 & - & - & 169 \\
\hline Pentecostal & 18.7 & 81.3 & - & - & 193 \\
\hline Other religion & 25.3 & 74.7 & - & - & 83 \\
\hline No religion & 24.3 & 75.7 & - & - & 74 \\
\hline Ethnic group & & & 0.443 & 0.506 & \\
\hline Shona & 23.0 & 77.0 & - & - & 710 \\
\hline Other & 19.7 & 80.3 & - & - & 74 \\
\hline Ever tested for HIV & & & 32.765 & 0.000 & \\
\hline Yes & 14.1 & 85.9 & - & - & 759 \\
\hline No & 31.3 & 68.7 & - & - & 25 \\
\hline $\begin{array}{l}\text { Approve of VCT prior to } \\
\text { MC }\end{array}$ & & & 0.072 & 0.788 & \\
\hline Yes & 19.3 & 80.7 & - & - & 171 \\
\hline No & 20.2 & 79.8 & - & - & 613 \\
\hline Ever heard of VMMC & & & 9.268 & 0.002 & \\
\hline Yes & 19.2 & 80.8 & - & - & 759 \\
\hline No & 44.0 & 56.0 & - & - & 25 \\
\hline Total & 157 & 627 & - & - & 784 \\
\hline Percentage & 20.0 & 80.0 & - & - & 100 \\
\hline
\end{tabular}

$\mathrm{VCT}$, voluntary counselling and testing; $\mathrm{MC}$, male circumcision; VMMC, voluntary medica male circumcision.

compared to those who belonged to medium and low wealth status $(80.6 \%$ and $75.7 \%$, respectively; $p<0.060)$. With respect to employment status, $26.6 \%$ of respondents who indicated that they were unemployed had low knowledge about male circumcision as compared to $16.4 \%$ of respondents who indicated that they were employed.

Eighty-six per cent of the respondents who had ever tested for HIV had high knowledge about male circumcision, compared to $68.8 \%$ of those who had never tested for HIV. Finally, $80.8 \%$ of the respondents who had heard of VMMC had high knowledge about male circumcision.

\section{Predictors of knowledge about male circumcision}

Table 4 shows the results of the binary regression examining the influence of sociodemographic characteristics and knowledge
TABLE 4: Predictors of knowledge about male circumcision.

\begin{tabular}{|c|c|c|c|}
\hline Variable & B & SE & $\operatorname{Exp}(B)$ \\
\hline \multicolumn{4}{|l|}{ Age } \\
\hline $30-35(R)$ & - & - & - \\
\hline $15-19$ & -0.361 & 0.386 & 0.697 \\
\hline $20-24$ & -0.316 & 0.342 & 0.729 \\
\hline $25-29$ & -0.552 & 0.321 & $0.576 * * *$ \\
\hline \multicolumn{4}{|l|}{ Marital status } \\
\hline \multicolumn{4}{|l|}{ Never married (R) } \\
\hline Married or living together & 0.379 & 0.289 & 1.461 \\
\hline Formerly married & 0.077 & 0.552 & 1.080 \\
\hline \multicolumn{4}{|l|}{ Education } \\
\hline Higher (R) & - & - & - \\
\hline Primary & -1.503 & 0.559 & $0.223 *$ \\
\hline Secondary & -1.231 & 0.402 & $0.292 *$ \\
\hline \multicolumn{4}{|l|}{ Wealth } \\
\hline \multicolumn{4}{|l|}{ High (R) } \\
\hline Low & -0.209 & 0.249 & 0.811 \\
\hline Medium & -0.004 & 0.248 & 0.996 \\
\hline \multicolumn{4}{|l|}{ Employment status } \\
\hline Unemployed (R) & - & - & - \\
\hline Employed & 0.201 & 0.231 & 1.223 \\
\hline \multicolumn{4}{|l|}{ Religion } \\
\hline No religion $(\mathrm{R})$ & - & - & - \\
\hline Mainline & 0.426 & 0.342 & 1.531 \\
\hline Pentecostal & 0.321 & 0.359 & 1.378 \\
\hline Apostolic sect & 0.245 & 0.351 & 1.277 \\
\hline Other Christian & 0.024 & 0.399 & 1.024 \\
\hline \multicolumn{4}{|l|}{ Ethnic group } \\
\hline Other (R) & - & - & - \\
\hline Shona & 0.175 & 0.316 & 1.191 \\
\hline \multicolumn{4}{|l|}{ Ever tested for HIV } \\
\hline No (R) & - & - & - \\
\hline Yes & 0.660 & 0.215 & $1.934^{*}$ \\
\hline \multicolumn{4}{|l|}{ Approve of VCT prior to MC } \\
\hline Disapprove (R) & - & - & - \\
\hline Approve & 0.187 & 0.233 & 1.205 \\
\hline \multicolumn{4}{|l|}{ Ever heard of VMMC } \\
\hline \multicolumn{4}{|l|}{ No $(R)$} \\
\hline Yes & 1.255 & 0.465 & $3.508^{*}$ \\
\hline \multicolumn{4}{|c|}{ Perception of risk to HIV infection } \\
\hline No, not at risk at all (R) & - & - & - \\
\hline Yes, at high risk & -0.085 & 0.322 & 0.919 \\
\hline Yes, at low risk & -0.041 & 0.215 & 0.960 \\
\hline \multicolumn{4}{|c|}{ Attitude towards male circumcision } \\
\hline \multicolumn{4}{|l|}{ Unfavourable attitude (R) } \\
\hline Favourable attitude & 0.177 & 0.197 & 1.194 \\
\hline \multicolumn{4}{|l|}{ Circumcision status } \\
\hline No (R) & - & - & - \\
\hline Yes & 0.577 & 0.333 & $1.782 * * *$ \\
\hline Constant & 0.511 & 0.810 & 1.667 \\
\hline Observations & 784 & - & - \\
\hline Nagelkerke & 0.13 .9 & - & - \\
\hline $\mathrm{H}-\mathrm{L}$ G gof test & 0.993 & - & - \\
\hline
\end{tabular}

VCT, voluntary counselling and testing; $\mathrm{MC}$, male circumcision; VMMC, voluntary medical male circumcision; H-L G gof, Hosmer-Lemeshow Goodness of fit test; $B$, beta values; $R$ reference category.

${ }^{*} p<0.05,{ }^{* * *} p<0.1$

about male circumcision. The results concerning age and knowledge about male circumcision showed that men aged 25-29 years were significantly less likely to have high knowledge about male circumcision compared to those aged 30-35 years. The odds of young men aged 25-29 years having high knowledge about male circumcision were $42 \%$ lower 
(odds ratio $[\mathrm{OR}]=0.576, p<0.1$ ) compared to those aged 30-35 years. Education was significantly related to knowledge about male circumcision. The results showed that the odds of youth with primary education having high knowledge of HIV were $78 \%$ lower $(\mathrm{OR}=0.223, p<0.05)$ compared to those with higher education. In addition, youth who reported having secondary education and having high knowledge about male circumcision were $71 \%$ lower $(\mathrm{OR}=0.292, p<0.05)$ compared to those with higher education and having high knowledge about male circumcision.

Further, the odds of young men who reported ever having tested for HIV having high knowledge about male circumcision were $93 \%$ higher $(\mathrm{OR}=1.93, p<0.05)$ compared to those who had never tested for HIV. With respect to ever having heard of VMMC, the odds of youth who had ever heard about VMMC compared to those who had not having high knowledge about male circumcision were 250\% higher $(\mathrm{OR}=3.50, p<0.05)$. Youth who reported being circumcised were more likely $(\mathrm{OR}=1.78, p<0.1)$ to have high knowledge about male circumcision compared to those who were uncircumcised, with $78 \%$ higher odds.

Table 5 presents the frequency distribution for respondents' perception of risk for HIV infection. Fifty-four per cent of the respondents perceived themselves not to be at risk of HIV infection compared to $10.4 \%$ who indicated that they were at a higher risk. About a third (35.6\%) perceived themselves to be at low risk of HIV infection.

Table 6 shows that there was a significant association between the background characteristics and perception of risk to HIV infection. Perception of low risk and high risk of HIV infection increased with increase in age. For example, 67.6\%, 23.6\% and $8.8 \%$ of young people aged 15-19 years indicated that they were at no risk, low risk and high risk to HIV infection, respectively. On the other hand, $44.2 \%, 42.5 \%$ and $13.3 \%$ of those aged 30-35 years indicated that they were at no risk, low risk and high risk for HIV infection, respectively.

With respect to marital status, while about a third (30.8\%) of formerly married men indicated that they were at high risk of HIV infection, only $10 \%$ of never-married men and the same proportion of men married or living together indicated that they were at high risk of HIV infection. Forty-three per cent of married men indicated that they were at a low risk of HIV infection, while $31.9 \%$ of never-married men indicated that they were at low risk of HIV infection.

There is a positive relationship between education and risk perception of HIV infection. Nearly half $(49.6 \%)$ of the respondents with higher levels of education indicated that

\begin{tabular}{lcc}
\multicolumn{4}{l}{ TABLE 5: Perception of risk of HIV infection. } \\
\hline Perception of risk to HIV infection & Frequency & Percentage \\
\hline No risk at all & 423 & 54.0 \\
Low risk & 279 & 35.6 \\
High risk & 82 & 10.4 \\
\hline Total & $\mathbf{7 8 4}$ & $\mathbf{1 0 0 . 0}$ \\
\hline
\end{tabular}

they were at low risk of HIV infection compared to about a third $(32.5 \%)$ of respondents with secondary education and close to two-fifths $(37.8 \%)$ of those with primary education.

There was a significant relationship between employment status and perception of risk of HIV infection (significant at $p<0.001)$. Forty-one per cent of employed youth perceived themselves to be at low risk $(40.8 \%)$, and $11.2 \%$ perceived themselves to be at high risk of HIV infection. On the other hand, $29 \%$ of the unemployed youth perceived themselves to be at low risk, compared to $9.6 \%$ who perceived themselves to be at high risk of HIV infection.

A similar proportion of respondents who had ever tested for HIV (10.6\%) and those who had never tested (9.5\%) indicated that they were at a high risk of HIV infection. Additionally, $42.1 \%$ of those who had ever tested for HIV reported that they were at a low risk. With those who had never tested for HIV, $47.3 \%$ and $9.5 \%$ indicated that they were at low risk and at high risk of HIV infection, respectively.

\section{Predictors of perception of risk of HIV infection}

Table 7 shows the results of a multinomial logistic regression model. The results show the relationship between the background characteristics and the perception of risk of HIV infection. In the model, the reference category for the dependent variable is 'No, not at risk at all'. The results showed that holding other variables constant, the odds of a man perceiving himself to be at a higher risk of HIV infection, relative to perceiving himself to be at no risk of HIV, were higher $(\mathrm{OR}=3.13, p<0.05)$ among formerly married young men than for never-married young men. Youth with secondary education were significantly less likely $(\mathrm{OR}=0.535$, $p<0.1$ ) to perceive themselves to be at higher risk compared to those with higher education. In addition, youth with primary education were significantly less likely $(\mathrm{OR}=0.530$, $p<0.05)$ to perceive themselves to be at low risk compared to those with higher education.

With regard to religion, the odds of a Pentecostal Christian perceiving himself to be at higher risk were $66 \%(p<0.05)$ lower compared to young men who did not profess any religious faith. On the other hand, the odds of apostolic sect youth perceiving themselves to be at low risk of HIV infection were lower by $49 \%(p<0.05)$ compared to young men who did not belong to any religion. The odds of Shona youth perceiving themselves to be at low risk of HIV infection compared to young men who belonged to other ethnic groups were $45 \%$ lower $(p<0.05)$. Further, the odds of young men perceiving themselves to be at low risk of HIV infection relative to perceiving themselves to be at no risk were $102 \%$ higher $(\mathrm{OR}=2.01, p<0.05)$ for those who had ever been tested for HIV than for those who had never been tested for HIV. The odds of youth who approved of VCT prior to male circumcision were less likely $(\mathrm{OR}=0.486, p<0.05)$ to perceive themselves to be at a higher risk of HIV infection compared to their counterparts who did not approve of it. 
TABLE 6: Background characteristics by perception of risk to HIV infection.

\begin{tabular}{|c|c|c|c|c|c|c|}
\hline Variable & No risk (\%) & Low risk (\%) & High risk (\%) & $\chi$-value & $p$ & Total \\
\hline Age & & & & 24.193 & 0.000 & 182 \\
\hline 15-19 & 67.6 & 23.6 & 8.8 & - & - & 229 \\
\hline $20-24$ & 55.5 & 35.8 & 8.7 & - & - & 192 \\
\hline $25-29$ & 48.4 & 40.1 & 11.5 & - & - & 181 \\
\hline $30-35$ & 44.2 & 42.5 & 13.3 & - & - & - \\
\hline Marital status & & & & 21.891 & 0.000 & \\
\hline Never married & 58.4 & 31.9 & 9.7 & - & - & 263 \\
\hline Married or living together & 47.1 & 43.0 & 9.9 & - & - & 26 \\
\hline Formerly married & 23.4 & 45.8 & 30.8 & - & - & 495 \\
\hline Education & & & & 17.487 & 0.002 & \\
\hline Primary & 56.8 & 37.8 & 5.4 & - & - & 37 \\
\hline Secondary & 57.1 & 32.5 & 10.4 & - & - & 618 \\
\hline Higher & 38.0 & 49.6 & 12.4 & - & - & 129 \\
\hline Wealth status & & & & 1.970 & 0.741 & \\
\hline Low & 55.1 & 34.8 & 10.1 & & & 276 \\
\hline Medium & 56.0 & 34.7 & 9.3 & - & - & 248 \\
\hline High & 50.8 & 36.8 & 12.4 & - & - & 260 \\
\hline Employment status & & & & 14.431 & 0.001 & \\
\hline Employed & 48.1 & 40.8 & 11.1 & - & - & 439 \\
\hline Unemployed & 61.4 & 29.0 & 9.6 & - & - & 345 \\
\hline Religion & & & & 12.154 & 0.144 & \\
\hline Mainline & 53.2 & 37.0 & 9.8 & - & - & 265 \\
\hline Pentecostal & 55.4 & 37.9 & 6.7 & - & - & 169 \\
\hline Apostolic sect & 58.6 & 29.6 & 11.8 & - & - & 193 \\
\hline Other religion & 54.2 & 31.3 & 14.5 & - & - & 83 \\
\hline No religion & 41.9 & 43.2 & 14.9 & - & - & 74 \\
\hline Ethnicity & & & & 4.964 & 0.084 & \\
\hline Shona & 55.1 & 34.4 & 10.5 & - & - & 710 \\
\hline Other & 43.2 & 47.3 & 9.5 & - & - & 74 \\
\hline Ever tested for HIV & & & & 30.315 & 0.000 & \\
\hline Yes & 47.3 & 42.1 & 10.6 & - & - & 759 \\
\hline No & 43.2 & 47.3 & 9.5 & - & - & 25 \\
\hline Approve of VCT prior to MC & & & & 5.103 & 0.078 & \\
\hline Yes & 57.9 & 31.6 & 10.5 & - & - & 171 \\
\hline No & 52.9 & 36.8 & 10.3 & - & - & 613 \\
\hline Ever heard of VMMC & & & & 3.471 & 0.176 & \\
\hline Yes & 53.4 & 36.1 & 10.5 & - & - & 759 \\
\hline No & 72.0 & 20.0 & 8.0 & - & - & 25 \\
\hline Number (Total) & 423 & 279 & 82 & - & - & 784 \\
\hline Percentage & 54.0 & 35.6 & 10.4 & - & - & 100 \\
\hline
\end{tabular}

VCT, voluntary counselling and testing; $\mathrm{MC}$, male circumcision; VMMC, voluntary medical male circumcision.

\section{Discussion}

This study sought to examine youths' knowledge about male circumcision and perception of risk of HIV infection on the one hand, and selected background characteristics, on the other. In the Zimbabwean context, little is known about the impact of background characteristics on social variables related to knowledge of male circumcision and perception of risk of HIV infection among urban men aged 15-35 years, despite the fact that this is a key subpopulation in the fight against HIV. While some studies have looked at these social variables related to male circumcision, ${ }^{26}$ it is mostly among different subpopulations, only included as predictor variables or not as exhaustive and critically analysed as done in the present study.

Knowledge about male circumcision appeared to increase with age. Youth aged 15-19, 20-24 and 25-29 years all were less likely to have high knowledge about male circumcision.
However, only youth aged 25-29 years compared to those aged 30-35 years were less likely to have high knowledge about male circumcision. Studies elsewhere show contrary findings. For example, one study in particular ${ }^{27}$ found no significant association between age and knowledge about male circumcision among young people and adults surveyed in rural Uganda. The differences in these results could have been attributed to the differences in the context of the studies and the definition of youth. 'Youth' in the study was defined as men aged 14-24 years and 'adults' as those aged 24 years and above.

Furthermore, the findings showed that youth with primary and secondary education were less likely to have knowledge about male circumcision compared to those with a higher level of education. One study observed similar relationships in Zimbabwe among soccer players, with those with higher education levels having more knowledge about male circumcision compared to those with lower levels 
TABLE 7: Predictors of perception of risk of HIV infection.

\begin{tabular}{|c|c|c|c|c|c|c|}
\hline \multirow[t]{2}{*}{ Variable } & \multicolumn{3}{|c|}{ Yes, at higher risk $95 \% \mathrm{Cl}$} & \multicolumn{3}{|c|}{ Yes, at low risk $95 \% \mathrm{Cl}$} \\
\hline & $\operatorname{Exp}(B)$ & LB & UB & $\operatorname{Exp}(B)$ & LB & UB \\
\hline \multicolumn{7}{|l|}{ Age } \\
\hline $30-35(R)$ & - & - & - & - & - & - \\
\hline $15-19$ & 0.588 & 0.223 & 1.551 & 0.733 & 0.379 & 1.419 \\
\hline $20-24$ & 0.561 & 0.254 & 1.241 & 0.886 & 0.526 & 1.491 \\
\hline $25-29$ & 0.813 & 0.400 & 1.651 & 0.888 & 0.553 & 1.426 \\
\hline \multicolumn{7}{|l|}{ Marital status } \\
\hline Never married (R) & - & - & - & - & - & - \\
\hline Married or living together & 0.727 & 0.364 & 1.452 & 1.090 & 0.693 & 1.714 \\
\hline Formerly married & $3.135^{*}$ & 1.054 & 9.324 & 1.252 & 0.455 & 3.443 \\
\hline \multicolumn{7}{|l|}{ Education } \\
\hline Higher (R) & - & - & - & - & - & - \\
\hline Primary & 0.282 & 0.054 & 1.467 & $0.530 *$ & 0.223 & 1.258 \\
\hline Secondary & $0.535 * * *$ & 0.264 & 1.085 & 0.487 & 0.306 & 0.776 \\
\hline High (R) & - & - & - & - & - & - \\
\hline Low & 0.905 & 0.481 & 1.701 & 1.123 & 0.738 & 1.707 \\
\hline Medium & 0.777 & 0.419 & 1.441 & 1.016 & 0.679 & 1.522 \\
\hline \multicolumn{7}{|l|}{ Employment status } \\
\hline Unemployed (R) & - & - & - & - & - & - \\
\hline Employed & 1.330 & 0.719 & 2.461 & 1.317 & 0.884 & 1.963 \\
\hline \multicolumn{7}{|l|}{ Religion } \\
\hline No religion (R) & - & - & - & - & - & - \\
\hline Mainline & 0.532 & 0.225 & 1.259 & 0.664 & 0.366 & 1.203 \\
\hline Pentecostal & $0.343^{*}$ & 0.132 & 0.891 & 0.657 & 0.353 & 1.222 \\
\hline Apostolic sect & 0.598 & 0.248 & 1.446 & $0.518^{*}$ & 0.277 & 0.970 \\
\hline Other religion & 0.719 & 0.267 & 1.939 & 0.582 & 0.281 & 1.208 \\
\hline \multicolumn{7}{|l|}{ Ethnicity } \\
\hline Other (R) & - & - & - & - & - & - \\
\hline No (R) & - & - & - & - & - & - \\
\hline Yes & 1.197 & 0.678 & 2.113 & $2.016^{*}$ & 1.377 & 2.953 \\
\hline \multicolumn{7}{|l|}{ Approval of VCT prior to MC } \\
\hline Disapprove (R) & - & - & - & - & - & - \\
\hline Approve & $0.486^{*}$ & 0.238 & 0.994 & 1.000 & 0.683 & 1.464 \\
\hline \multicolumn{7}{|l|}{ Ever heard of VMMC } \\
\hline No (R) & - & - & - & - & - & - \\
\hline Yes & 1.402 & 0.298 & 6.590 & 2.415 & 0.847 & 6.890 \\
\hline \multicolumn{7}{|l|}{ Knowledge about MC } \\
\hline Low knowledge (R) & - & - & - & - & - & - \\
\hline High knowledge & 1.121 & 0.601 & 2.090 & 1.058 & 0.696 & 1.607 \\
\hline \multicolumn{7}{|l|}{ Attitude towards MC } \\
\hline Unfavourable attitudes (R) & - & - & - & - & - & - \\
\hline Favourable attitudes & 0.651 & 0.391 & 1.085 & 0.879 & 0.634 & 1.218 \\
\hline \multicolumn{7}{|l|}{ Circumcision status } \\
\hline No (R) & - & - & - & - & - & - \\
\hline Yes & 0.796 & 0.399 & 1.150 & 0.862 & 0.343 & 1.430 \\
\hline Observations & 784 & - & - & - & - & - \\
\hline Pearson & 0.112 & - & - & - & - & - \\
\hline Deviance & 0.833 & - & - & - & - & - \\
\hline
\end{tabular}

of education. ${ }^{28}$ Educational attainment predisposes individuals to appreciate health programmes better. ${ }^{29}$

The findings from this study also showed that previously testing for HIV was associated with knowledge about male circumcision. Respondents who had ever tested for HIV were more likely to be knowledgeable about male circumcision. This could be attributed to counselling sessions that happen before and after testing. In Zimbabwe, VCT centres disseminate information about male circumcision. Male circumcision services have also been an integral part of male sexual and reproductive health programmes. ${ }^{30}$ Information about the importance of reduction in the number of sexual partners, provision of condoms, delay in 
sexual debut and early diagnosis of STIs is disseminated during VCT sessions and in some cases male circumcision. ${ }^{3}$ The likelihood is that those who have ever been tested for HIV were informed or educated about the availability of male circumcision as an option to prevent HIV infection.

In addition, ever having heard of VMMC was found to be statistically significantly associated with knowledge about male circumcision. Youth who had ever heard of VMMC were more likely to have high knowledge of male circumcision compared to those had never heard of it. This could be a result of availability of different mass media advertisement about VMMC. According to a study in Zimbabwe among respondents aged 15-49 years in rural and urban areas, a higher proportion of the respondents had heard of VMMC. ${ }^{26}$

As expected, youth who were circumcised were knowledgeable about male circumcision in comparison to those who were uncircumcised. The present findings are consistent with other research, which found that males who were circumcised were more likely to have high levels of knowledge about male circumcision. ${ }^{14}$ Perhaps the reason why circumcised youth have high knowledge about male circumcision is as a result of intensive information dissemination by health professionals before circumcision takes place in health institutions in Zimbabwe.

The findings suggest marital status had a significant influence on perception of risk of HIV infection. For example, formerly married youths were more likely to perceive themselves to be at higher risk of HIV infection compared to those who had never married. However, previous findings have found that, in general, people tend to underestimate their risk of HIV. ${ }^{31,32}$

In addition, the present study found that education influences perception of risk of HIV infection. For instance, youth with secondary education were less likely to perceive themselves to be at a higher risk of HIV infection compared to respondents with higher education. However, youth with primary education were less likely to perceive themselves to be at low risk of HIV infection compared to those with both secondary and higher education. As education increases, the young men are more likely to perceive themselves to be at high risk of HIV infection, most likely because they understand the dynamics of HIV infection. However, these results are inconsistent with previous studies; for instance, a study among military personnel in Nigeria found an inverse relationship between educational attainment and HIV risk perception..$^{33}$ Results from that study found that those with higher education were less likely to perceive themselves to be at high risk of HIV infection.

Furthermore, the results showed religious variations in perception of risk of HIV infection. Youth who belonged to Pentecostal churches and apostolic sects were less likely to perceive themselves to be at a higher risk of HIV infection compared to respondents with no religion. However, the findings of the current study do not support previous research, which found that these men perceived themselves to be at no risk for HIV infection. ${ }^{34}$ Apostolic sect members usually put stringent restrictions on sexual behaviour, which make them believe that they are not at risk of HIV infection. ${ }^{34}$ For instance, they encourage intermarriage within the church, virginity tests for young girls, polygamy practices and use of the Holy Spirit to detect adultery. This has implications for young men affiliated to the apostolic sect's perception of HIV infection. Studies have shown that religion impacts on human behavioural and health outcomes. ${ }^{35}$

With regard to Pentecostal Christians, the findings of the current study are consistent with those of a previous study, which also found that Pentecostal Christians perceived themselves to be at low risk of HIV infection. Plausibly, the association between low perception of risk of HIV infection and Pentecostalism could be attributed to their teachings on nurturing religious experiences and strong synergies encouraged among members. Socialisation of congregants towards more frequent and overlapping interactions can discourage members' involvement in risky sexual behaviours and hence impact on their perception of risk of HIV infection. ${ }^{36}$

Youth belonging to the Shona ethnic group were less likely to perceive themselves to be at low risk of HIV infection compared to other ethnic groups, which perceived itself to be at no risk of HIV infection. Perhaps the Shona perception of risk of HIV infection is not surprising considering the fact that in Zimbabwe and other sub-Saharan Africa communities they have cultural practices conducive to the spread of HIV such as wife inheritance, which involves relatives of the deceased husband marrying the widow. ${ }^{37}$ In most cases, condoms are not used in this new relationship, because they are not usually used among married couples. ${ }^{38}$ If the widow's first husband died from HIV, she would be more likely to transmit HIV and/or STIs to the new husband. The practice of wife inheritance is also prevalent in the Bondo District in Kenya. ${ }^{39}$

In addition, those who had ever tested for HIV were more likely to perceive themselves to be at low risk of HIV infection compared to those who had never tested. This relationship could be explained by the fact that HIV is highly stigmatised. Hence, ever taking the test and obtaining negative HIV results makes men aged 15-35 years feel they are not at risk of HIV infection. With respect to approval of VCT prior to male circumcision, respondents who approved of VCT prior to circumcision were less likely to perceive themselves to be at risk of HIV infection compared to those who did not approve of it. Perhaps those who approve of VCT prior to circumcision are youth who regularly check their status and for that reason perceive themselves to be at low risk of HIV infection.

\section{Conclusion}

The findings identified a knowledge deficit about male circumcision among youth with primary and secondary education, indicating the probability of low uptake of male circumcision as an HIV intervention measure in Harare. 
Furthermore, as education increases, youth are more likely to perceive themselves to be at high risk of HIV infection. The study recommends the need to strengthen perceived susceptibility to HIV across all educational levels, and advocacy is needed on health benefits of male circumcision.

\section{Acknowledgements}

The authors would like to thank the following research assistants: Tapiwa Chirenje, Washington Dune, Kudzai Ndemera, Josphat Jekera and Tapiwa Mangombe.

\section{Competing interests}

The authors declare that they have no financial or personal relationship(s) that may have inappropriately influenced them in writing this article.

\section{Authors' contributions}

K.M. made conceptual contributions, data analysis and led the writing process. I.K.-S. contributed substantially to the writing and reviewing of the article.

\section{References}

1. UNAIDS. UNAIDS global AIDS update. Geneva: World Health Organization; 2016.

2. UNAIDS. UNAIDS report on the global AIDS epidemic. Geneva: World Health Organization; 2013.

3. Zimbabwe National AIDS Council, Zimbabwe Ministry of Health and Child Welfare, UNAIDS, World Food Programme VAM Food Security Analysis, CDC. Smart investment to end HIV/AIDS in Zimbabwe [homepage on the Internet]. Harare; 2015. Available from: http://www.nac.org.zw/sites/default/file/Hot $\% 20$ spot $\% 20$ 2015. Available from: http:/

4. Cameron DW, D'Costa L, Maitha G, et al. Female to male transmission of human immunodeficiency virus type 1: Risk factors for seroconversion in men Lancet. 1989;2(8660):334, 403-407. https://doi.org/10.1016/S0140-6736(89)90589-8

5. Easton L, Kalichman SC. Behavioral aspects of male circumcision for the prevention of HIV infection. Curr HIV/AIDS Rep. 2009;6:187-193. https://doi.org/10.1007/ s11904-009-0025-9

6. Moses S, Bradley JE, Nagelkerke NJD, Ronald AR, Ndinya-Achola JO, Plummer FA Geographical patterns of male circumcision practices in Africa: Association with HIV seroprevalence. Int J Epidemiol. 1990;19:693-697. https://doi.org/10.1093/ ije/19.3.693

7. Auvert B, Taljaard D, Lagarde E, Sobngwi-Tambekou J, Sitta R, Puren A. Randomized controlled intervention trial of male circumcision for reduction of HIV infection risk: The ANRS 1265 trial. PLoS Med. 2005;2:e298. https://doi.org/10.1371/ journal.pmed.0020298

8. Bailey R, Moses S, Parker CB, et al. Male circumcision for HIV prevention in young men in Kisumu, Kenya: A randomised controlled trial. Lancet. 2007;369:643-656. https://doi.org/10.1016/S0140-6736(07)60312-

9. Gray R, Kigozi G, Serwadda D, et al. Male circumcision for HIV prevention in men in Rakai, Uganda: A randomised trial. Lancet. 2007;369:657-666. https://doi. org/10.1016/S0140-6736(07)60313-4

10. Andersson N, Cockcroft A. Male circumcision, attitudes to HIV prevention and HIV status: A cross-sectional study in Botswana, Namibia and Swaziland. AIDS Care. 2012;24:301-309. https://doi.org/10.1080/09540121.2011.608793

11. Bridges JFP, Selck FW, Gray GE, McIntyre JA, Martinson NA. Condom avoidance and determinants of demand for male circumcision in Johannesburg, South Africa. Health Pol Plan. 2011;26:298-306. https://doi.org/10.1093/heapol/czq064

12. Khumalo-Sakutukwa G, Lane T, van-Rooyen, $H$, et al. Understanding and addressing socio-cultural barriers to medical male circumcision in traditionally non-circumcising rural communities in sub-Saharan Africa. Cult Health Sex. 2013;15. https://doi.org/10.1080/13691058.2013.807519

13. Mavhu W, Buzdugan R, Langhaug LF, et al. Prevalence and factors associated with knowledge of and willingness for male circumcision in rural Zimbabwe. Trop Med Int Health. 2011:16:589-597. https://doi.org/10.1111/j.1365-3156.2011.02744.x

14. Futures Group. Soka Uncobe: Understanding barriers to uptake of male circumcision services. Swaziland: Futures Group; 2012.
15. Naidoo PV, Dawood F, Driver C, Narainsamy M, Ndlovu S, Ndlovu V. Knowledge, attitudes and perceptions of pharmacy and nursing students towards male circumcision and HIV in a KwaZulu-Natal University, South Africa. Afr J Prim Health Care Fam Med. 2012;4:327. https://doi.org/10.4102/phcfm.v4i1.327

16. Keetile M, Rakgoasi S. Male circumcision; Willingness to undergo safe male circumcision and HIV risk behaviours among men in Botswana. Afr Popul Stud. 2014;28:1345-1361. https://doi.org/10.11564/0-0-630

17. Lundsby K, Dræbel T, Meyrowitsch DW. 'It brought joy in my home as in the area of my wife'. How recently circumcised adult men ascribe value to and make sense of male circumcision. Glob Public Health. 2012;7:352-366. https://doi.org/10.10 80/17441692.2011.632638

18. Macintyre, K, Andrinopoulos, K, Moses, et al. Attitudes, perceptions and potentia uptake of male circumcision among older men in Turkana County, Kenya using qualitative methods. PLoS One. 2014;9:e83998. https://doi.org/10.1371/journal. pone.0083998

19. Tieu HV, Phanuphak N, Ananworanich J, et al. Acceptability of male circumcision for the prevention of HIV among high-risk heterosexual men in Thailand. Sex Transm Dis. 2010;6:352-355. https://doi.org/10.1097/OLQ.0b013e3181c9963a

20. Westercamp M, Agot KE, Ndinya-Achola J, Bailey RC. Circumcision preference among women and uncircumcised men prior to scale-up of male circumcision for HIV prevention in Kisumu, Kenya. AIDS Care. 2012;24:157-166. https://doi.org/1 $0.1080 / 09540121.2011 .597944$

21. Bartlett S, 2010. Editorial: Responding to urban youth's own perspectives. Environ Urban. 2010;22:307-316. https://doi.org/10.1177/0956247810381211

22. Kish L. Survey sampling. New York: John Wiley \& Son, Inc; 1995.

23. Hoffman J, Arendse K, Larbi C, Johnson N, Vivian LM. Perceptions and knowledge of voluntary medical male circumcision for HIV prevention in traditionally noncircumcising communities in South Africa. Glob Public Health. 2015;10:692-702. https://doi.org/10.1080/17441692.2015.1014825

24. MacCallum RC, Zhang S, Preacher KJ, Rucker DD. On the practice of dichotomization of quantitative variables. Psychol Methods. 2002;7:19-40. https://doi.org/ 10.1037/1082-989X.7.1.19

25. Streiner DL. Breaking up is hard to do: The heartbreak of dichotomizing continuous data. Can J Psychiatry. 2002;47:262-266. https://doi.org/10.1177/07067437020 4700307

26. Hatzold K, Mavhu W, Jasi P, et al. Barriers and motivators to voluntary medical male circumcision uptake among different age groups of men in Zimbabwe: Results from a mixed methods study. PLoS One. 2014;9(5):e85051. https://doi. org/10.1371/journal.pone.0085051

27. Wilcken A, Miiro-Nakayima F, Hizaamu RN, Keil T, Balaba-Byansi D. Male circumcision for HIV prevention - A cross-sectional study on awareness among young people and adults in rural Uganda. BMC Public Health. 2010;10(1):209. https://doi.org/10.1186/1471-2458-10-209

28. Kaufman ZA, DeCelles J, Bhauti K, Weiss HA, Chaibva CN, Ross DA. P3.373 Male circumcision prevalence, knowledge, perceptions, and intent among men in
Bulawayo, Zimbabwe: A cross-sectional study. Sex Transm Infect. 2013;89(Suppl Bulawayo, Zimbabwe: A cross-sectional study. Sex Transm Infect
1):A2666. https://doi.org/10.1136/sextrans-2013-051184.0826

29. McGill N. Education attainment linked to health throughout lifespan: Exploring social determinants of health. Nations Health. 2016;46:1-9.

30. MOHCW. Zimbabwe policy guidelines on safe and voluntary male circumcision. Harare: Ministry of Health and Child Welfare; 2009.

31. Ijadunola DKT, Abiona TC, Odu OO, ljadunola MY. College students in Nigeria underestimate their risk of contracting HIV/AIDS infection. Eur J Contracept Reprod Health Care. 2007;12:131-137. https://doi.org/10.1080/1362518060 1068461

32. Sychareun V, Thomsen S, Chaleunvong K, Faxelid E. Risk perceptions of STIS/HIV and sexual risk behaviours among sexually experienced adolescents in the northern part of LaoPDR. BMC Public Health. 2013;13:1126. https://doi.org/ 10.1186/1471-2458-13-1126

33. Essien EJ, Ogungbade GO, Ward D, et al. Influence of educational status and other variables on HIV risk perception among military personnel: A large cohort finding. Mil Med. 2007;172:1177-1181. https://doi.org/10.7205/MILMED.172.11.1177

34. Gore OT, Chiweshe MK, Mangundu M, Mangundu A. Acceptability of medical male circumcision within the Apostolic marange sect in Zimbabwe; A qualitative study. Glob Inst Res Educ. 2014;3:128-133.

35. Trinitapoli J, Regnerus MD. Religion and HIV risk behaviors among married men: Initial results from a study in rural Sub-Saharan Africa. I Sci Study Relig. 2006;45:505-528. https://doi.org/10.1111/j.1468-5906.2006.00325.x

36. Garner RC. Safe sects? Dynamic religion and AIDS in South Africa. J Mod Afr Stud. 2000;38:41-69. https://doi.org/10.1017/S0022278X99003249

37. Drew DS, Foster G, Chitima J. Cultural practices associated with death in the North Nyanga district of Zimbabwe and their impact on widows and orphans. J Soc Dev Afr. 1996;11:79-86.

38. Exavery A, Kanté AM, Jackson E, et al. Role of condom negotiation on condom use among women of reproductive age in three districts in Tanzania. BMC Public Health. 2012;12:1097. https://doi.org/10.1186/1471-2458-12-1097

39. Agot KE, Vander Stoep A, Tracy M, et al. Widow inheritance and HIV prevalence in Bondo district, Kenya: Baseline results from a prospective cohort study. PLoS One. 2010;5:e14028. https://doi.org/10.1371/journal.pone.0014028 